\title{
Volumen 17
}

\section{Menéndez Pidal en la percepción del P. Batllori}

Francisco Abad Nebot

(UNED)

\section{PRESENTACIÓN}

La Galeria de Personatges de Miquel Batllori apareció en 1975, y luego - con alguna supresión y bastantes añadidos - como volumen XVII de su «Obra Completa». El conjunto es de gran interés, y da ocasión para sucesivos comentarios: Croce, Menéndez Pidal, Torras i Bages, Marańón, Maravall, d'Abadal, Vicens y muchas otras figuras y autores, aparecen aquí en su semblanza y en su obra escrita; bastantes cosas pueden comentarse a partir de lo que dice nuestro autor de ellos y acerca de ellos mismos. Se nos permitirá - no obstante - detenernos de momento en Menéndez Pidal, y glosar tanto lo que a su propósito estampa el P. Batllori como otros hechos que conciernen al maestro gallego-asturiano.

\section{POR LA FILOLOGIA Y LA LINGUUtSTICA}

Las páginas de temática pidalina quedaron escritas por Batllori en 1969, y tuvieron una primera publicación en $1970^{2}$; están reproducidas luego con notas en ambas versiones de la Galeria... Como puede suponerse, tales páginas surgieron a ráz de la muerte de don Ramón, y constituyen un repaso de su vida y de su obra.

Nota el P. Batllori cómo Pidal fue alumno y discípulo de Menéndez Pelayo, a quien veneró siempre, pero que lo super 6 «como lingtlista y como filologo»"; en efecto asl ocurre. Don Marcelino era un historiador crecido en el siglo XIX, y le importó sobre todo tanto lo ideológico-filos6́fico como lo literario; su sen-

I Galeria..., Barcelona, Ed. Vicens Vives, 1975; Valencia, Eliseu Climent, 2000. Citamos por esta segunda edición.

2 Spanische Forschungen der Görresgesellschaft, erste Reihe, Gesammelte Aufsütze zur Kulturgeschichte Spaniens, 25, 1970; hay separata - que manejamos y por la que citamos - en la Biblioteca Central del CSIC.

3 «Don Ramón Menéndez Pidal 1869-1968», Spanische Forschungen..., p. 1 de la separata (no hemos visto el tomo completo, y no sabemos si la paginación es coincidente). 
sibilidad era ajena a los problemas lingüísticos y de la edición de textos, al margen de que la lingúística neogramática entonces vigente aún no se había introducido en España, y él no la introdujo porque sus intereses espirituales iban por otra parte. Menéndez Pelayo participó de las tendencias ideocráticas que se manifestaron en la cultura española en los años setenta del Ochocientos: en la novela de Galdós de entonces, por ej. ${ }^{4}$ Menéndez Pidal fue justamente quien trajo hasta nosotros la linguística positivista y en general la linglística cientifica tout court, aunque antes en Hispanoamérica no pueden olvidarse los dos nombres señeros de Andrés Bello y - en lo que más nos importa ahora- de Rufino José Cuervo (por otra parte Pidal falsaría y superaría más tarde el estricto positivismo filológico). Menéndez Pidal ya de joven quiso ser y fue un filólogo muy riguroso, interesado en la edición de textos, en el análisis lingüístico, en el análisis de la tradición de esos textos, etc.: estos saberes eran ajenos a don Marcelino, y por eso ha podido mantenerse que hay en parte una continuidad entre Menéndez Pidal y Milá. Manuel Alvar insistió en la línea de continuidad Milá, Menéndez Pelayo y Menéndez Pidal ${ }^{5}$, pero Dámaso Alonso - con buen juiciosubrayó las quiebras y discontinuidades entre Menéndez Pelayo y Pidal.

En cualquier caso ya decimos que a don Marcelino le era más cercana la historia ideológica y filosófica, de tal manera que por ej. José Luis Abellán ha podido mantener que «Menéndez Pelayo se ha hecho acreedor con su gigantesca obra al título de "fundador" de la Historia de la filosofía en España»; ${ }^{6}$ cabe mantener ciertamente que en cuanto el interés por lo filológico y lo idiomático, Menéndez Pidal superó a su maestro don Marcelino, aunque éste a su vez tuviese una preocupación por el pasado religioso español que fue ajena al discípulo.

\section{HISTORIOGRAFIA E IDEOGRAFIA}

Hablando de Pidal en relación a Menéndez Pelayo, el P. Batllori concreta aún que

lo siguió muy de cerca en la concepción idealista de la historia de España, si bien desde diverso punto de vista. Para Menéndez Pelayo el hilo conductor de su pensamiento en la historia de la cultura española había sido la identificación del espíritu nacional con el espíritu católico; Menéndez Pidal lo halló en la perduración de la unidad de España a través de la conciencia imperial de la monarquía leonesa, herencia de la unidad visigótica, que en el siglo XI se trasplanto a Castilla la Nueva con la conquista de Toledo?

\footnotetext{
4 Para estos años iniciales de la Restauración cfr. las páginas de José Maria Jover Zamora en el vol. VIII de la Historia de Espafia dirigida por M. Tunón de Lara, Barcelona, Labor, reimpresión de 1990.

s Cfr. su El romancero. Tradicionalidad y pervivencia, Barcelona, Planeta, 1970, pp. 17-54.

6 J. L. ABELLAN, Historia critica del pensamiento espatiol, 1, Madrid, Espasa-Calpe, 1979, p. 54.

1 «Don Ramón...», la misma p. 1.
} 
Estamos en ambos casos - se nos dice - ante historiografías idealistas, es decir, atentas a la historia del pensamiento más que a la historia de los hechos materiales (fundamentos demográficos y económicos, ordenación social, etc.), y en esto fue mejor don Marcelino que su discipulo. En efecto y aunque Menéndez Pelayo concibió el pasado español en su dimensión de logros histórico-literarios y de ortodoxia católica indentada por la existencia de los «heterodoxos españoles», algunas veces estimo los factores e intereses concretos actuantes por ej. en la Reconquista; Menéndez Pidal por contra hizo una historiografía que denominaremos - si vale el neologismo- ideográfica, esto es, descriptiva de ideas, atenta nada más que a lo que pensaban las minorías cultas de las proximidades del Rey de cada momento: el pasado concebido por don Ramón era el de las concepciones políticas, el de los propositos de acción política, cuando en realidad lo verdaderamente histórico no es sólo el propósito, la ley, etc., sino su cumplimiento o su no cumplimiento.

En este sentido que apuntamos escribió una vez Menéndez Pidal que «siempre lo que [un gobernante] se propuso, lo que en su acción vieron los que le rodeaban, es lo esencial ${ }^{8}$ : estamos ciertamente ante el análisis de los designios, de las ideas, de las concepciones ideales, cuando la realidad viene motivada por intereses que muchas veces se oponen a esas concepciones idealizadas. Menéndez Pidal estimaba que debía atenderse a las ideaciones del entorno de los gobernantes, mientras Menéndez Pelayo aludió en general y a veces de manera expresa a los intereses inmediatos actuantes.

Jaume Vicens supo captar estas diferencias que a veces se daban entre don Marcelino y don Ramón, y lo hizo en particular a propósito del libro pidalino $E l$ imperio hispánico y los Cinco Reinos ${ }^{9}$. Las palabras de Vicens resultan muy gráficas, $y$ por eso las recogemos en abreviatura:

Para comprender [don Marcelino la realidad de la Reconquista,] se situaba en la humildad y dureza de la vida en los reinos cristianos del Norte [...]. *Guardar su pan de cada días era para aquellos guerreros una obligación no sólo imprescindible, sino honrosa. [...] Don Ramón se ha visto obligado a declarar «decadente» a don Marcelino y a buscar por su cuenta y riesgo una nueva explicación a la historia medieval española. Su última obra demuestra que quien tiene razón no es el discípulo sino el maestro; don Marcelino y no don Ramón. El presidente de la Real Academia hace un alarde de erudición que nadie le regatea, pero sus argumentos son muy poco convincentes. [...] Persigue [...] un fantasma filológico-cancilleresco que nada tiene que ver con la realidad ${ }^{10}$.

Menéndez Pidal inicia en efecto su obra disintiendo de la interpretación de quien llama "gran maestro», Menéndez Pelayo: el santanderino rechaza ciertamente que en los hombres altomedievales de los siglos XI o XII se diese una idea consciente de reconquista, pues solo estaban guiados por el instinto de la posesión

- Ramón Mentandez Pidal, Los Reyes Católicos y otros estudios, Buenos Aires, Espasa-Calpe, 1962, p. 11.

- Publicado en Madrid, Instituto de Estudios Políticos, 1950.

10 J. Vicens Vives, Obra dispersa, II, Barcelona, Ed. Vicens Vives, 1967, pp. 186-187. 
de las realidades concretas como el terreno que tenían delante y el sustento cotidiano, etc. Frente a esto don Ramón postula el sacar a luz «los principios políticos» que regian en los siglos remotos, uno de los cuales «es la idea imperial nacida entre los siglos IX y X»: es preciso descubrir tal institución imperial, proclama ${ }^{11}$.

Estamos por tanto y según hemos avanzado ante una historiografia que se puede denominar ideográfica, a la que le importan sólo y se queda solo en los principios y las ideas políticos, cuando la realidad no se halla constituida nada más que por las ideas y las instituciones, y desde luego la sustancia de lo histórico es tanto el cumplimiento como la transgresión de lo institucional.

La concepción historiografica pidalina se ve bien por ej. en este otro párrafo, en el que pide que no se hable de la Edad Media española «prescindiendo de los textos» medievales, ya que

en ellos insistentemente se muestra que si la invasión musulmana destruy6 la unidad visigótica, la empresa reconquistadora operó a través de los siglos como principio cohesivo de los pueblos en ella empeñados, dando a España una individualidad superior a su disgregación ${ }^{12}$.

Se trata asi de una historiografia filologica, que atiende a los textos y a sus exposiciones doctrinales, de propósitos, etc. Pidal se mueve en una concepción filológica e ideográfica, y no hace falta decir que en las antípodas de esa idea se hallaba el Vicens sobre todo maduro, atento a lo contemporáneo y a la historia social y económica (la historia social le habia importado casi siempre). ${ }^{13}$

M. Batllori caracteriza en todo caso a las historiografías de Menéndez Pelayo y de Menéndez Pidal de kidealistas» o idealizantes, no atentas en lo fundamental - asi - a lo social-económico, etc ${ }^{14}$. La otra caracterización que hace de ellas es por su contenido fundamental: la cultura española es cultura católica para don Marcelino, mientras para don Ramón la idea historiográfica vertebral es la de la unicidad española. Desde luego el santanderino tuvo una significación política por su adhesión a la concepción católica del pasado español y de lo que él creía la esencia de lo español; en esto Menéndez Pidal resultó muy distinto, pues él (que venía de la familia conservadora y poderosa de los Pidal) enlazo en definitiva con la tradición krausista-institucionista y con la burguesía liberal y laica de izquierdas. El gusto por lo popular o folclórico, por lo colectivo - la juglaría en vez del arte literario clerical -, por las costumbres tradicionales, etc., deriva de su impregnación por el krausismo español casi más que de su noventayochismo ${ }^{15}$.

"El imperio hispanico..., pp. 7-11.

12 Ibid.

13 En la Galeria..., el P. Batllori manifiesta en referencia a J. Vicens que edesde 1950 cl orientó toda su escuela hacia una primacia de lo económico-social. Adoptó la metodologfa estadística de la historia cconómica, pero en el fondo prefirió siempre la actitud más humanística y más humana de Lucien Febvre y de Fernand Braudel (p. 313).

14 Bl propio Vicens llevó a cabo una debelación del carficter filologico e institucional de la historiografil medriletia (don Ramón, Śnchez Albomoz y Valdeavellano, Jover), además de su castellanocentrismo.

is En todo caso la impregnación noventayochista de don Ramón es cierta, como hace bastantes afios apunto Jose Luis Abellán, y en nuestros días descubre con entusiasmo algón filblogo: vid. J. L. Abellán, La industria cultural en Espanta, Madrid, Edicusa, 1975, pp. 256 y ss. 


\section{UNA ESCUELA CIENTIFICA}

La semblanza pidalina que hace Batllori continúa con la afirmación de que don Marcelino fue «un filologo y un historiador», mientras «Menéndez Pidal, ya desde sus primeros escritos, [fue] un hombre de ciencia del siglo $\mathrm{XX}_{\Perp}{ }^{16}$, y estas referencias resultan exactas. A Menéndez Pelayo le importaba la filologfa en el sentido de que gustaba de la literatura y de los problemas literarios, y llevó a cabo así una herculea tarea acerca de la historia de las ideas estéticas, de los líricos castellanos, de la novela de la serie castellana, ...; además de esto es un historiador de la filosofía y de las ideas - según decimos-estéticas, y de las religiosas (los que él consideraba «heterodoxos españoles»), etc.

Menéndez Pidal incorporó los estudios españoles a los estudios internacionales de lingúística, y sus paradigmas teóricos se encuentran vigentes cien años más tarde: aunque retocables en asuntos concretos y de detalle, el Manual de gramática histórica, los Ortgenes del español, y la Historia de la lengua suya proxima a editarse resultan textos maestros, insustituidos y vigentes. S6lo por desconocimiento puede explicarse que en alguna Universidad se les hurte a los alumnos el imprescindible Manual pidalino, lo mismo que - por razones más complejas - cuando nosotros cursábamos la carrera nunca se nos habló en las aulas de la Historia de la lengua de Lapesa. Don Ramón fue en efecto un hombre de ciencia del siglo XX, y la ciencia linguística cabe datarla entre nosotros con su obra.

Al repasar el P. Batllori la biografía pidalina, tiene que referirse a su pertenencia a los órganos rectores de la Junta para Ampliación de Estudios, y luego a su dirección del «Centro de Estudios Históricos»: «Ese Centro será hasta 1936 - escribe - el verdadero centro de las actividades cientfficas de Menéndez Pidal, un seminario extrauniversitario, pero de hecho parauniversitario, en el que los mejores alumnos de su cátedra se hacían sus discípulos»17. Efectivamente la llamada «escuela de Madrid» o «escuela española» de filología es la que se constituy6 en torno a don Ramón a partir de 1910 en el «Centro de Estudios Históricos» de la Junta; podemos recordar algún dato al respecto.

La «Junta...» qued6 creada en 1907, y el «Centro de Estudios Históricos» surgió en su seno con la revitalización de la misma en marzo de 1910; la Memoria de esa JAE de 1910-1911, habla primero de una «Seccion» en el «Centro» llamada de «Orígenes de la lengua española» y que estaba dirigida por $D$. Ramón Menéndez Pidal; años más adelante la Sección cambiará de nombre ${ }^{18}$. En estos tiempos de Sección dedicada a los origenes de la lengua española, la Memoria de los años sucesivos registra una acumulación de distintos investigadores que con una u otra cualidad se hallan vinculados a la misma; don Ramón

\footnotetext{
16 Loc. cit., de nuevo la p. 1.

17 Loc. cit., p. 2.

10 Las Memorias editadas por la JAE resultan una fuente de información de consulta necesaria.
} 
figura como director, y otros estudiosos que van apareciendo en tales Memorias son Tomás Navarro Tomás, Américo Castro, Federico Ruiz Morcuende, Justo Gómez Ocerín, Federico de Onís, Antonio García Solalinde, Florentino Castro Guisasola, Zacarfas García Villada, Miguel Artigas o Eduardo García de Diego' ${ }^{19}$.

Llega un momento - Memoria correspondiente á [...] 1914 y 1915 - en que en efecto se habla ya de $D$. Ramón Menéndez Pidal en tanto «Presidente del Centro y Director de la Sección de Filología» del mismo; entonces figura Navaro como «Secretario del Centro». Desde este momento los nombres de investigadores que formaban parte de la sección filológica siguen aumentando, y aunque sea en algún caso creemos que por una sola vez, aparecen ciertamente registrados Benito Sánchez Alonso, Samuel Gili Gaya, Amado Alonso, Eduardo Martínez Torner, José F. Montesinos, Manuel Manrique de Lara, Vicente García de Diego, Emilio Alarcos García, Miguel Herrero García, Ernesto Giménez Caballero, Dámaso Alonso, Pedro Henríquez Ureña, Juan Dantín Cereceda, Pedro Sánchez Sevilla, José F. Pastor, Carmen Fontecha, Pedro U. González de la Calle, Agustín Millares Carlo, Rafael Lapesa, Homero Serís, Pedro Salinas, Lorenzo R. Castellano, Enriqueta Hors, Enrique Moreno Báez, Salvador Fernández Ramírez, etc.; adscrito a la sección creada en los últimos tiempos de «Literatura contemporánea», aparece asimismo Vicente Llorens ${ }^{20}$.

En una nómina tan amplia como la que constituyen las dos enumeraciones parciales anteriores debe haber colaboradores más o menos ocasionales, mientras otros constituyen el núcleo que se tiene por esencial del Centro de Estudios Históricos.

La escuela pidalina se hizo posible al amparo institucional de la Junta, y de ella surgió lo mejor de la filología española durante muchas décadas del siglo XX; aún a primeros del siglo XXI han podido publicarse textos de Lapesa, de Álvaro Galmés, de Diego Catalán, e inéditos de don Ramón. No obstante la trivialidad del olvido, el rechazo que a veces despiertan las personas moralmente humildes y desinteresadas como Rafael Lapesa, la comodidad de no leer una obra escrita y publicada muy amplia, etc., han llevado a pretericiones de varios miembros de esta escuela en las décadas finales del siglo XX, y en ocasiones a faltas de respeto hacia ellos (de algunas somos testigos personales).

El «Centro de Estudios Históricos» reunió en sí, además de al grupo de los filologos, a historiadores medievalistas y de las instituciones, del arte, etc.: don Claudio Sánchez Albornoz y con él Valdeavellano, don Manuel Gómez Moreno y tantos otros nombres, trabajaron alli y por ej. don Claudio hizo asimismo escuela. Las ciencias humanas en España durante un cuarto largo de siglo tuvieron su asiento principal en este Centro - el propio Ortega o los arabistas cola-

19 Varios de los volúmenes de la Memoria correspondiente a los años [...] de la Junta para Ampliación de Estudios é Investigaciones Científicas -volúmenes generalmente bianuales-, hemos podido adquirirlos en librería de viejo; otros que nos faltaban aún por ver los hemos localizado en la Biblioteca Nacional o en los Institutos Miguel de Cervantes y Zurita del CSIC.

20 A don Vicente dedico su discurso de recepción en la Academia Claudio Guillén: De la continuidad, Madrid, RAE, 2003; no obstante es posible afiadir más cosas. 
boraron en algún momento en él-; disuelto por los vencedores de la guerra civil, quienes estuvieron vinculados al mismo o bien formaron parte luego de la España peregrina, o bien hicieron su obra en solitario's.

\section{TAREAS COLECTIVAS}

Registra el P. Batllori en tanto fruto colectivo del «Centro» la Revista de Filologia Española fundada por el propio Menéndez Pidal, y la pondera como «superior por su método a las que entonces aparecían en España ${ }^{22}$; ya está dicho que en verdad la lingüística y la filología cientificas y actuales datan entre nosotros de la obra personal pidalina, ampliada luego con el trabajo de sus grandes discípulos directos. Inmediatamente nota Batllori que la elección de Menéndez Pidal en «el año 1925 como director de la Real Academia Española, representa no sólo el triunfo de su alta personalidad científica [...,] sino el dominio de su escuela filológica en toda España».

Obra por supuesto de la Academia de la lengua es el nuevo Diccionario histórico, pero Miquel Batllori percibe que «del ensamblaje de [la escuela pidalina] con la tradición académica ha nacido el grande Diccionario historico de la lengua española ${ }^{23}$; se trata de una percepción certera, si bien tal ensamblaje viene de más atrás.

En efecto hay un trasvase de las concepciones de la escuela pidalina a las tareas de la Real Academia, por ej. en el DRAE de 1925 y luego en el de $1936 / 1939$, en la adopción del propio nombre de «lengua española» en vez del de «lengua castellana», etc. Incluso la incorporación a la propia Academia de persona como Vicente García de Diego - investigador independiente, pero vinculado al «Centro de Estudios Históricos»-, fue un empeño individual de don Ramón de cara a poder contar con sus saberes etimologicos y dialectales ${ }^{24}$.

21 Para los avatares por ej. del trabajo pidalino - afectada por el rechazo franquista - vid. D. Catalán, El archivo del nomancero [,] patrimonio de la humanidad, Madrid, Fundación Menéndez Pidal, MMI.

Dámaso Alonso no obstante se acercó pronto al CSIC; nunca lo hizo Rafael Lapesa. Catalán piensa en una obra anterior suya que la linguística oficial española estuvo dirigida desde los años cincuenta y desde el CSIC, por Rafael de Balbin y Manuel Alvar (Alvar coincide en su temática filológico-diacrónica y dialectal con la orientación fundamental de la escuela de don Ramón).

2 Loc. cit., p. 2.

23 Loc. cit., la misma p. 2.

24 Constituye un error grave y banal minusvalorar en ocasiones la obra de don Vicente por el hecho de que no ocupase una cátedra universitaria. 


\section{DOCUMENTOS Y ANÁLISIS LINGỨSTIICOS}

Hay dos páginas del escrito de Miquel Batllori que venimos glosando ${ }^{25}$, dedicadas a enumerar varias de las obras linguísticas pidalinas. Cita desde luego el llamado primeramente Manual elemental de gramática histórica espaniola (1904), y dice del mismo que es «libro fundamental más bien que elemental»; tiene absoluta razón el P. Batllori: estamos ante un texto casi centenario y completamente vigente hoy en día, insuperado además en cuanto tal. Pueden añadírsele precisiones, pero el cuadro de conjunto queda como decimos sin superar todavía; no da nada por sabido, por lo que pedagógicamente resulta el manual más indicado en su género para una iniciación y fundamentación en la materia.

Como es lógico alude asimismo nuestro autor a las dos grandes recopilaciones de textos y documentos hechas en el «Centro de Estudios Históricos» con don Ramón a la cabeza: los Documentos lingú́sticos del reino de Castilla (a los que hay que añadir los de Aragón publicados personalmente por Tomás Navarro Tomás cuatro lustros después de la guerra), y la Crestomatía del español medieval. Los Documentos lingúlísticos del reino castellano no sólo importan por sf mismos, sino que llevan además introducciones a cada una de sus partes escritas personalmente por Menéndez Pidal, y que abordan cuestiones de geografía histórica muy precisas y preciosas.

Más en detalle (aunque no siempre con apreciaciones exactas) alude Batllori al estudio magno pidalino Orlgenes del español, el cual - califica - «constituyó una piedra miliar en el camino de la filología hispánica y aun de la románica en general». Origenes... consta de cuatro partes, a saber: I. Textos. II. Gramática. III. Regiones y Épocas. IV. Conclusiones. En la primera se edita en efecto una muestra especialmente representativa de fuentes, y al análisis de grafías, fonética, morfología y sintaxis, y lexicología, se dedica la segunda y fundamental; la tercera sintetiza los datos históricos, geográficos e idiomáticos en prodigiosa síntesis, mientras la cuarta reflexiona teoréticamente sobre el estado linglístico presentado antes.

La diacronía y la fragmentación lingúística peninsulares se hallan en muy estrecha dependencia de la historia toda y de la geografía, y ese es el marco global que - por lo que se refiere a la lengua general patrimonial - dibuja con percepción maestra Menéndez Pidal; atiende lo mismo a la mixtura vasco-románica que influye decisivamente en la diacronía del español, $y$ de hecho un tomito de estudios En torno a la lengua vasca lo organizó más tarde ${ }^{26}$. Asimismo sobre la Toponimia prerrománica hispana hizo otra obra mayor. ${ }^{27}$

«Regiones y épocas» constituye - según decimos - una síntesis integradora de datos de diferente naturaleza que se interrelacionan; realmente los Docu-

2s Se trata de las pp. 3-4.

26 Buenos Aires, Espasa-Calpe, 1962.

$n$ Madrid, Gredos, 1952 y 1968 (reimpresión). 
mentos lingüísticos de Castilla, aunque faltos del análisis idiomático, forman por sí solos y con las introducciones parciales que llevan, otra especie de exposición de las regiones en la diacronía del español. Con esta parte de «Regiones y épocas» principalmente, hizo a su vez nuestro autor el volumen $E l$ idioma español en sus primeros tiempos ${ }^{23}$, precioso texto luego reeditado hasta casi nuestros días, en que muy lamentablemente la obra pidalina se encuentra casi por entero fuera del mercado.

Pocos años antes de Ortgenes..., don Manuel Gómez Moreno publicó en el propio «Centro» sus Iglesias Mozárabes ${ }^{29}$; esta obra no estaba referida sólo a lo artístico, sino que llevaba también algunos apuntes de historia de la cultura, y debio estimular a Menéndez Pidal para hacer la suya (esos Orfgenes...) y para hacerla como la hizo. Gómez Moreno hablaba de un arte mozárabe que iba de los tiempos de Abderrahman II hasta los de la ruina del Califato, o sea, de kentre 850 y 1030 , que es en buena medida el mismo tiempo examinado por don Ramón en Orígenes; además y según el concepto de nuestro arqueólogo, se trató de un perfodo en el que «se nacionaliz6 España ${ }^{30}$. Las presentes ideas de la llamada nacionalización peninsular, del relieve por tanto de lo mozárabe, etc., ya decimos que debieron estimular a Menéndez Pidal e incidir en sus planes de trabajo; la importancia de lo mozárabe asimismo quedaría subrayada andando los años por J. A. Maravall.

\section{LA INACABADA HISTORIA DE LA LENGUA}

No pudo hacer referencia el P. Batllori a la Historia de la lengua española pidalina, aunque fragmentos de la misma los tenfa publicados don Ramón desde los años treinta y de hecho había hecho mención expresa de la obra en proyecto; tal Historia, revisada y editada por Diego Catalán y colaboradores suyos, se encuentra por fin - al parecer - en pruebas de imprenta cuando escribimos.

Hay una visión de conjunto del pensamiento pidalino en los dos volúmenes de capítulos y fragmentos suyos - algunos inéditos entonces - editados como España y su historia ${ }^{31}$. Estamos ante un conjunto precioso en el que se atiende a lo histórico, lo literario y lo linglístico, y trazan una secuencia conceptual y de hechos que en buena medida y referida especificamente a lo idiomático es la que cabe esperar se encuentre en la *Historia de la lengua española.

España y su historia aborda los asuntos de «Hispania, provincia del Imperio romanow y de «Romanos y germanos», lo que sin duda constituye el marco

\footnotetext{
22 Madrid, Ed. Voluntad, 1927.

29 Iglesias..., Madrid, CEH, 1919. Ejemplar de la Bibliotoca Pablica del Estado de Málaga.

30 Op. cit., p. XV.

31 Madrid, Eds. Minotauro, 1957.
} 
más general en el que hay que situar la romanización y más tarde la germanización linguísticas (en este último caso manifiesta en algunos escasos vocablos góticos, en la toponimia, etc.). De hecho don Ramón distinguio en Origenes... ${ }^{32}$ la existencia de una «época visigótica» en la formación del español; en general los análisis monográficos pidalinos en torno a los siglos preliterarios del idioma y los que hizo en torno al llamado "Cantar de Mio Cid», constituyen la referencia fundamental para lo que ha de aparecer -en distinta redacción - en la *Historia de la lengua.

De los siglos XIII, XIV y XV sólo se encuentran publicados ya de esa obra pidalina los fragmentos referidos a Alfonso X y a Juan Ruiz, pero toda la parte que va de los Reyes Católicos hasta la muerte de Calderón se encuentran anticipados en buena medida en varios capítulos aparecidos en vida de don Ramón o bien póstumamente: lo referido al paso del retoricismo al humanismo, al lenguaje del siglo XVI y en particular en la época de Felipe II, a Madrid frente a frente a Sevilla en lo idiomático, y a la lengua barroca, lo conocemos en amplia medida según la interpretación del maestro gallego-asturiano ${ }^{33}$.

Don Ramón no prosiguió su obra de conjunto acerca de la diacronía de nuestra lengua más allá de 1680 , y ello debe deberse a varios motivos, el primero por supuesto el de que un trabajo desaloja a otro trabajo, y la dedicación a los temas del romancero y de la épica más a los «Prólogos» a los volúmenes de su Historia de España, absorbieron lo principal de sus afanes. Pero hay razones que no hemos visto nunca aludidas y que personalmente creemos que asimismo debieron operar.

A Menéndez Pidal el siglo XIX le era aún muy inmediato, y estudiarlo era estudiar a sus padres y parientes cercanos y estudiarse a sí mismo: necesitaba un mayor distanciamiento, necesitaba de una mínima perspectiva que le llevase a saber apreciar bien las proporciones de los hechos; por otra parte lo fundamental en la trayectoria del idioma se créa que acababa en el siglo XVII -sólo en nuestros dras empieza a hablarse de los cambios gramaticales acaecidos desde el

32 En el 103.

${ }^{33}$ En un artfculo que aparece en la revista filológica sevillana Cauce, hemos sintetizado sobre la cronología interna de la lengua a partir de especialistas como J. Herman y M. Banniard, y asimismo Menéndez Pidal, Lapesa, Diaz Diaz y C. Company:

a) El latín peninsular fue idioma usual hasta bien entrado el siglo VIII hispano.

b) Sólo desde fines del siglo XI comienzan [las] lenguas románicas en la Península (entiendase sobre todo: el castellano).

c) Existe una especie de frontera a partir de la cual la lengua se moderniza, y que hay que situar hacia finales de la Epoca de don Juan Manuel y Juan Ruiz (1320-1351), y hacia comienzos de la siguiente Epoca idiomática de Sem Tob y Juan Fernández de Heredia (1351-1385). Menéndez Pidal comprobo cómo -illo (en vez de -iello) llega a "invadir francamente la lengua literaria"; Lapesa estableció en su día el hecho de que desde la segunda mitad del siglo XIV [ ...], la literatura castellana no ofrece ya ordinariamente mas finales de palabra consonánticos que los admitidos por la lengua moderna; en fin y por ej. Concepción Company manifiesta cómo en [...] la evolución de la frase sustantiva, lo más relevante es que a mediados del siglo XIV se puede realizar el primer corte cronologico importante.

Desde entrado ya el Trescientos, por tanto, cabe señalar el inicio de la transformación del castellano medieval en la lengua espantola moderna. 
Seiscientos y el Setecientos hasta ahora -, y así lo posterior linguística y literariamente a Calderón se estimaba de menos importancia en sf y de menos relieve.

Pero ocurre además que la historiografía rechazaba en general el siglo XVIII por extranjerizante, y el XIX por liberal y caotico, y esa historiografía se mostraba bastante acorde en no atenderlos. Don Ramón exaltó en tanto se hallaba impregnado de una mentalidad historiografica romántica los tiempos medievales y la ejemplaridad de sus héroes (Rodrigo Díaz), y exaltó asimismo y nacionalistamente -en la traza de Menéndez Pelayo - el esplendor áureo del siglo XVI; lo posterior le resultó en general más ajeno, demasiado próximo, menos relevante, y todo esto le condujo (junto a otras motivaciones) a abandonar la redacción de su Historia de la lengua, lo que para el patrimonio de la cultura española constituye una perdida imposible de reparar.

\section{FINAL}

El P. Batllori decía en su artículo que constituye nuestro punto de partida que don Ramón «no buscaba la popularidad [..., ] sino la labor importante y bien hecha: la calidad de los temas y de su trabajo serán la clave de su éxito " ${ }^{34}$. No gusto en efecto de la popularidad que da la prensa, y ahí radico seguramente la clave del malentendido que Ortega y Gasset tuvo siempre con él; la austeridad de su esfuerzo resulta proverbial, y así repetía que lo que le gustaba era estar sentado a la mesa, sin viajes que interrumpiesen su labor. La popularidad viene cuando en efecto la labor está bien hecha y se refiere a asuntos de importancia, no a cuestiones laterales: él enfocó el pasado español todo y llego a sugerir enseñanzas de ese pasado para el presente, así como en texto tan señero como el de la Introducción a su Historia de España (1947) reclamó la vuelta a la normalidad civil y política.

No en todos los planteamientos científicos acertó don Ramón, pues eso le está impedido a todo ser humano, pero por su ciencia, por su talante civil y su ejemplaridad personal, Menéndez Pidal es uno de los españoles de todos los tiempos de vida más lograda. A él estuvo dedicado uno de los bellos caṕtulos del libro todo tan bello Galeria de Personatges de Miquel Batllori. 